\title{
Pathogenicity Determinants of Sclerotinia sclerotiorum and Their Association to Its Aggressiveness on Brassica juncea
}

\author{
Rupeet Gill (iD ${ }^{1 *}$, Prabhjodh S. Sandhu², Sanjula Sharma², and Pankaj Sharma \\ ${ }^{1}$ Department of Vegetable Science, Punjab Agricultural University, Ludhiana 141004, Punjab, India \\ ${ }^{2}$ DBT Centre of Excellence on Brassicas, Department of Plant Breeding and Genetics, Punjab Agricultural University, \\ Ludhiana 141004, Punjab, India
}

(Received on March 1, 2021; Revised on June 29, 2021; Accepted on July 5, 2021)

White rot or stem rot caused by Sclerotinia sclerotiorum is one of the most destructive fungal diseases that have become a serious threat to the successful cultivation of oilseed Brassicas. The study was designed with an aim to investigate the association between the pathogenic aggressiveness and pathogenicity determinants of this pathogen specifically in Brassica for the first time. For this, a total of 58 isolates of $S$. sclerotiorum from different geographical regions were collected and purified. These isolates were inoculated on a Brassica juncea cv. RL-1359 and they exhibited high level of variation in their disease progression. The isolates were grouped and then $\mathbf{2 4}$ isolates were selected for the biochemical analysis of pathogenicity determinants. The isolates varied significantly with respect to their total organic acids, oxalic acid production and pectin methyl esterase and polygalacturonase activity. The oxalic acid production corresponded to the disease progression of the isolates; the isolates with higher oxalic acid production were the more aggressive ones and vice-versa. This is, in our knowledge, the first study to establish a correlation between oxalic acid production and pathogenic ag-

*Corresponding author.

Phone) +91-8872470676

E-mail) rupeetgill@pau.edu

ORCID

Rupeet Gill

https://orcid.org/0000-0001-7261-6988

\section{Handling Editor : Jungkwan Lee}

(c) This is an Open Access article distributed under the terms of the Creative Commons Attribution Non-Commercial License (http:// creativecommons.org/licenses/by-nc/4.0) which permits unrestricted noncommercial use, distribution, and reproduction in any medium, provided the original work is properly cited.

Articles can be freely viewed online at www.ppjonline.org. gressiveness of $S$. sclerotiorum on $B$. juncea. However, the pectinases' enzyme activity did not follow the trend as of disease progression. These suggest an indispensable role of oxalic acid in pathogenicity of the fungus and the potential to be used as biochemical marker for preliminary assessment of pathogenic aggressiveness of various isolates before incorporating them in a breeding program.

Keywords : oxalic acid, pectin methyl esterase, polygalacturonase

Sclerotinia sclerotiorum (Lib.) de Bary, the causal of stem rot or white mould, is a non-host specific, necrotrophic soil-borne pathogen that attacks a wide range of cultivated and wild species including rapeseed-mustard. The fungus infects over 400 species of plants worldwide (Boland and Hall, 1994). Earlier, this disease was considered to be of little economic importance in rapeseed-mustard, but in recent years it has gained the importance of being the most wide-spread and destructive disease. In this crop, the disease manifests mainly as stem rot, resulting in crop lodging and severe losses. Yadav et al. (2011) reported yield losses up to $40 \%$, while in severe incidence, losses may go up to $74 \%$ (Sharma et al., 2001b).

The fungus produces hard resting structures; the sclerotia, that remain viable in the soil for many years. On imbibation of water from soil, sclerotia germinate either myceliogenically (produce mycelia) or carpogenically (produce apothecia) depending upon the environmental conditions (Steadman, 1983). Upon infection on stem, initially watersoaked lesions are formed which expand rapidly and are covered with whitish mycelial growth (Bolton et al., 2006). Mycelial infection in the field is generally very patchy, 
whereas ascosporic infection is more uniform. When the stem is completely girdled and covered by the whitish mycelial growth all over, the plant wilts and dries. The fungus produces symptoms on all the aerial plant parts but the most destructive ones are produced on the stem. Later in the season, sclerotia are formed inside the pith of the stem as well as on the outside mycelial growth on the infected tissue. Usually the plants are attacked at flowering stage and once the pathogen is established in the field, it is very difficult to eliminate it due to the stubborn soil-borne sclerotia and wide host range.

Though, cultural practices like crop rotation with grasses and management of irrigation along with the use of some fungicides, offers some reduction in disease severity, but effective management of this fungal disease is still lacking (Ando et al., 2007). The most sustainable and efficient way to manage this disease is host plant resistance (Li et al., 2006); thus, the first important step is identification of reliable sources of resistance and there-after incorporation in the elite cultivars. At present, there are no known sources of complete and robust resistance against it. However, partial resistance has been identified by various workers in mostly B. napus and very few in B. juncea (Li et al., 2006, 2008; Zhao et al., 2004). Identifying sources of resistance in Brassica against Sclerotinia is challenging due to the variability existing in the aggressiveness of the pathogen population. Thus, for effective screening of germplasm and identification of reliable resistance sources, it is very important to have an insight of the variability in the population. This has focused our attention on the need of detailed study and understanding of the pathogenic factors involved in disease development.

S. sclerotiorum is responsible for secreting a wide array of substances to facilitate its necrotrophic life style (Annis and Goodwin, 1997). Oxalic acid seems to be an indispensable pathogenicity determinant (Zhou and Boland, 1999). Corroboration of this involvement of oxalic acid is based upon the oxalate recovery from infected tissues in millimolar concentrations (Marciano et al., 1983). The positive correlation between oxalic acid and pathogenicity has also been strengthened by the study, where mutants of Sclerotinia lacking in the ability to synthesize oxalate were nonpathogenic, whereas, the revertant strains after regaining their oxalate biosynthetic ability, exhibited normal virulence (Godoy et al., 1990). The fungus primarily utilizes the mechanical pressure to penetrate the host cuticle; however, lytic enzymes are also known to play an important role in it (Saharan and Mehta, 2008). Tissue maceration, cell wall lysis, and solubilization of cell wall constituents is brought about by strong and repeated action of various lytic enzymes (Cessna et al., 2000). In this instance, cell wall degrading enzymes (CWDEs) including predominantly pectinases along with cellulases, hemicellulases, xylanases, glucanases etc. act and bring about maceration of the host tissue, followed by necrosis and ultimately death of the plant (Riou et al., 1991). Amongst pectinolytic enzymes, S. sclerotiorum is known to produce various isoforms of exo- and endo-polygalacturonases (PGs) and pectin methyl esterases (PME) (Waksman et al., 1991). The PME deesterifies the methylated pectin producing demethylated pectin, which is then acted upon by PG enzyme, breaking it down to galacturonic acid units, thus solubilizing the pectin as whole.

Keeping in view the above-mentioned, this study was designed (1) to evaluate the production of various pathogenicity determinants by different $S$. sclerotiorum isolates and (2) to establish an association between these and pathogenic aggressiveness of the isolates.

\section{Materials and Methods}

Evaluation of pathogenic aggressiveness of $S$. sclerotiorum isolates. In this study, a total of 58 isolates of $S$. sclerotiorum, collected from various rapeseed-mustard growing areas of Punjab and adjoining states were used (Table 1). B. juncea cv. RL 1359 was used to evaluate all the isolates of $S$. sclerotiorum for their pathogenic aggressiveness for two years. Plants were inoculated using standard stem inoculation technique (Buchwaldt et al., 2005). The inoculated plants were given frequent irrigations and sprinklers were used at regular intervals to maintain optimum humidity. Data was recorded as lesion length at 1, 2, and 3 weeks after inoculation and area under disease progression curve (AUDPC) was worked out for each isolate.

Total acids production. Total acids production was estimated by the procedure described by Durman et al. (2005). The isolates were grown on bromophenol blue (BPB) amended potato dextrose agar medium and incubated for 3 days in darkness at $22 \pm 2^{\circ} \mathrm{C}$. Observation on diameter of mycelial growth in the colony $(\mathrm{C})$ and yellow color developed $(\mathrm{Y})$ were measured and the ratio $(\mathrm{Y} / \mathrm{C})$ was used as a measure to compare different isolates for total acids production.

Oxalic acid and pectinase enzyme analysis. As followed by Sharma et al. (2001a), the production of oxalic acid, PG, and PME was standardized w.r.t. growth period of $S$. sclerotiorum. For this, a single isolate of S. sclerotiorum (SsAm) was grown and filtrate was extracted every 
Table 1. Isolates of Sclerotinia sclerotiorum and their place of collection

\begin{tabular}{|c|c|c|c|c|c|}
\hline S. no. & Name & Place of collection & S. no. & Name & Place of collection \\
\hline 1 & SsLd1 & PAU, Ludhiana, Punjab & 30 & SsLd2 & Ludhiana (B. napus), Punjab \\
\hline 2 & SsBh1 & Bharatpur 1, Rajasthan & 31 & $\mathrm{SsMh}$ & Mahua, Rajasthan \\
\hline 3 & $\mathrm{SsBh} 2$ & Bharatpur 2, Rajasthan & 32 & $\mathrm{SsHn}$ & Hantra, Bharatpur, Rajasthan \\
\hline 4 & $\mathrm{SsBa}$ & Bawal, Haryana & 33 & $\mathrm{SsHb}$ & Habibpur, Rajasthan \\
\hline 5 & SsAm & Rampur, Amritsar, Punjab & 34 & $\mathrm{SsSe}$ & Sewar, Bharatpur, Rajasthan \\
\hline 6 & SsBt1 & Bathinda 1, Punjab & 35 & $\mathrm{SsBj}$ & Borai, Bharatpur, Rajasthan \\
\hline 7 & SsFd & Faridkot, Punjab & 36 & SsSd & Salabaad, Bharatpur, Rajasthan \\
\hline 8 & SsLa & Ladhowal, Punjab & 37 & SsAl & Amoli, Bharatpur, Rajasthan \\
\hline 9 & SsHs1 & Hisar 1, Haryana & 38 & $\mathrm{SsBr}$ & Beri, Sikar, Rajasthan \\
\hline 10 & SsPn & Pant nagar, Uttarakhand & 39 & $\mathrm{SsHr}$ & Harsora, Alwar, Rajasthan \\
\hline 11 & $\mathrm{SsGj}$ & S K nagar, Surat, Gujarat & 40 & $\mathrm{SsKr}$ & Kiratpura, Jaipur, Rajasthan \\
\hline 12 & $\mathrm{SsBt} 2$ & Bathinda 2, Punjab & 41 & $\mathrm{SsPr}$ & Pathredi, Jaipur, Rajasthan \\
\hline 13 & SsHs2 & Hisar 2, Haryana & 42 & SsRt & Rajnauta, Jaipur, Rajasthan \\
\hline 14 & $\mathrm{SsBd}$ & Badesaron, Hoshiarpur, Punjab & 43 & SsMd & Mandha, Jaipur, Rajasthan \\
\hline 15 & $\mathrm{SsSp}$ & Sehajpur, Patiala, Punjab & 44 & SsAd & Arauda, Bharatpur, Rajasthan \\
\hline 16 & $\mathrm{SsCk}$ & Chownkiman, Ludhiana, Punjab & 45 & SsBd1 & Badnagar, Jaipur, Rajasthan \\
\hline 17 & SsMk & Mahal kalan, Barnala, Punjab & 46 & $\mathrm{SsBn}$ & Bheem nagar, Ujjain, Madhya Pradesh \\
\hline 18 & SsMa & Maluka 1, Bathinda, Punjab & 47 & $\mathrm{SsCw}$ & Chhonkar wara, Bharatpur, Rajasthan \\
\hline 19 & SsSw1 & Singhawala 1, Moga, Punjab & 48 & SsLw & Ludhawai, Bharatpur, Rajasthan \\
\hline 20 & SsJg & Jagraon, Ludhiana, Punjab & 49 & SsJa & Jhlara, Shajapur, Madhya Pradesh \\
\hline 21 & SsSw2 & Singhawala 2, Moga, Punjab & 50 & $\mathrm{SsSh}$ & Shergarh, Jodhpur, Rajasthan \\
\hline 22 & SsRj & Rajoana, Ludhiana, Punjab & 51 & SsMw & Mandawar, Dausa, Rajasthan \\
\hline 23 & $\mathrm{SsDt}$ & Dhatt, Ludhiana, Punjab & 52 & $\mathrm{SsSb}$ & SR 25 - Sarasa, Bikaner, Rajasthan \\
\hline 24 & SsMl & Malke, Moga, Punjab & 53 & $\mathrm{SsSi}$ & SR 12 - Sitara, Bharatpur, Rajasthan \\
\hline 25 & SsMo & Moga, Punjab & 54 & SsKa & SR 21 - Kangra, Himachal Pradesh \\
\hline 26 & $\mathrm{SsBp}$ & Bagha purana, Moga, Punjab & 55 & $\mathrm{SsBe} 3$ & Sr 1 - Berhampore, West Bengal \\
\hline 27 & SsMt & Matwani, Moga, Punjab & 56 & $\mathrm{SsBe} 2$ & SR 3 - Berhampore, West Bengal \\
\hline 28 & $\mathrm{SsBm}$ & Bhumbli, Gurdaspur, Punjab & 57 & SsKt & Kathua, Jammu and Kashmir \\
\hline 29 & $\mathrm{SsSt}$ & Sathiali, Gurdaspur, Punjab & 58 & SsAg & Agra, Uttar Pradesh \\
\hline
\end{tabular}

day up to 10 days of incubation for determination of oxalic acid content and pectinases activity.

For oxalic acid determination, the filtrate was obtained by growing isolates in potato dextrose broth for 3 days. The filtrate was centrifuged and the supernatant was analyzed using the procedure described by Xu and Zhang (2000). The mycelium dry weight was recorded after keeping it at $80^{\circ} \mathrm{C}$ for $72 \mathrm{~h}$. For enzymatic analysis, the isolates were grown in Czapek dox's broth with $1 \%$ pectin as sole carbon source for 7 days. The activity of PME and PG was estimated by the methods described by Desse and Stahmann (1962) and Miller (1959), respectively.

Statistical analysis. All assays were run in triplicate and data was subjected to analysis of variance (ANOVA) and compared using the Duncan grouping test at 5\% probability $(P<0.05)$, with the assistance of the SAS program
(SAS Institute Inc., Cary, NC, USA).

\section{Results}

Aggressiveness studies of $S$. sclerotiorum isolates. The isolates of $S$. sclerotiorum differed considerably w.r.t. the disease progression on B. juncea cv. RL 1359 (Table 2, Fig. 1). The AUDPC values across the isolates in both seasons exhibited a range from 29.76 (SsHn) to 115.89 (SsBj). The isolates were categorized into five different groups based upon their AUDPC values (Table 3).

Analysis of pathogenicity determinants. For this biochemical analysis, 24 representative isolates were selected from different groups based on the AUDPC values and were further used (Table 3). 
Table 2. Area under disease progression curve for Sclerotinia sclerotiorum isolates on Brassica juncea cv. RL 1359 (season 1 \& 2)

\begin{tabular}{|c|c|c|c|c|c|c|c|}
\hline S. no. & Isolate & $\begin{array}{c}\text { AUDPC } \\
\text { (season 1) }\end{array}$ & $\begin{array}{c}\text { AUDPC } \\
\text { (season 2) }\end{array}$ & S. no. & Isolate & $\begin{array}{c}\text { AUDPC } \\
\text { (season 1) }\end{array}$ & $\begin{array}{c}\text { AUDPC } \\
\text { (season 2) }\end{array}$ \\
\hline 1 & SsLd1 & 65.78 & 73.60 & 30 & SsLd2 & 86.34 & 95.67 \\
\hline 2 & SsBh1 & 31.12 & 34.23 & 31 & $\mathrm{SsMh}$ & 73.04 & 80.35 \\
\hline 3 & $\mathrm{SsBh} 2$ & 91.37 & 106.92 & 32 & SsHn & 29.76 & 31.89 \\
\hline 4 & $\mathrm{SsBa}$ & 39.28 & 42.00 & 33 & $\mathrm{SsHb}$ & 31.90 & 34.23 \\
\hline 5 & SsAm & 98.49 & 103.00 & 34 & $\mathrm{SsSe}$ & 90.43 & 101.12 \\
\hline 6 & SsBt1 & 94.30 & 108.70 & 35 & $\mathrm{SsBj}$ & 97.23 & 115.89 \\
\hline 7 & $\mathrm{SsFd}$ & 85.17 & 95.98 & 36 & $\mathrm{SsSd}$ & 55.43 & 62.62 \\
\hline 8 & SsLa & 55.62 & 61.84 & 37 & SsAl & 44.54 & 45.12 \\
\hline 9 & SsHs1 & 68.96 & 79.34 & 38 & $\mathrm{SsBr}$ & 71.37 & 78.17 \\
\hline 10 & $\mathrm{SsPn}$ & 75.84 & 88.28 & 39 & $\mathrm{SsHr}$ & 93.34 & 106.56 \\
\hline 11 & $\mathrm{SsGj}$ & 67.48 & 75.45 & 40 & $\mathrm{SsKr}$ & 48.62 & 52.12 \\
\hline 12 & $\mathrm{SsBt} 2$ & 80.90 & 90.23 & 41 & $\mathrm{SsPr}$ & 53.87 & 57.95 \\
\hline 13 & SsHs2 & 73.90 & 82.06 & 42 & SsRt & 46.09 & 48.23 \\
\hline 14 & $\mathrm{SsBd}$ & 70.59 & 77.64 & 43 & SsMd & 61.65 & 73.12 \\
\hline 15 & $\mathrm{SsSp}$ & 70.01 & 78.17 & 44 & SsAd & 66.90 & 74.67 \\
\hline 16 & $\mathrm{SsCk}$ & 63.75 & 71.50 & 45 & SsBd1 & 57.18 & 65.73 \\
\hline 17 & SsMk & 37.73 & 41.23 & 46 & $\mathrm{SsBn}$ & 65.15 & 68.45 \\
\hline 18 & SsMa & 86.88 & 95.28 & 47 & $\mathrm{SsCw}$ & 103.45 & 110.84 \\
\hline 19 & SsSw1 & 77.01 & 85.17 & 48 & SsLw & 60.48 & 68.84 \\
\hline 20 & SsJg & 55.04 & 62.62 & 49 & SsJa & 84.59 & 95.28 \\
\hline 21 & SsSw2 & 34.23 & 36.56 & 50 & SsSh & 86.92 & 96.06 \\
\hline 22 & SsRj & 44.54 & 45.12 & 51 & SsMw & 96.45 & 107.34 \\
\hline 23 & $\mathrm{SsDt}$ & 75.65 & 83.23 & 52 & $\mathrm{SsSb}$ & 69.03 & 77.78 \\
\hline 24 & SsMl & 84.01 & 94.89 & 53 & $\mathrm{SsSi}$ & 92.18 & 104.23 \\
\hline 25 & SsMo & 79.53 & 82.84 & 54 & SsKa & 59.12 & 71.17 \\
\hline 26 & $\mathrm{SsBp}$ & 57.75 & 66.50 & 55 & $\mathrm{SsBe} 3$ & 89.94 & 100.14 \\
\hline 27 & SsMt & 51.92 & 48.62 & 56 & $\mathrm{SsBe} 2$ & 78.37 & 86.34 \\
\hline 28 & $\mathrm{SsBm}$ & 67.67 & 75.45 & 57 & SsKt & 99.76 & 108.12 \\
\hline 29 & $\mathrm{SsSt}$ & 46.87 & 59.89 & 58 & SsAg & 68.50 & 77.10 \\
\hline
\end{tabular}

AUDPC, area under disease progression curve.

Standardization. It was observed that oxalic acid production increased up to 3 days of incubation while pectinases' activity increased up to 7 days of incubation and declined as growth further progressed (Fig. 2). Therefore, for analysis of all the isolates, filtrate was obtained at 3 days and 7 days of incubation for oxalic acid and pectinases, respec-

Table 3. Grouping of isolates according to their AUDPC values on Brassica juncea cv. RL-1359

\begin{tabular}{ccrl}
\hline Group & AUDPC & No. & \multicolumn{1}{c}{ Isolates } \\
\hline 1 & $20-40$ & 4 & $\mathrm{SsBh}^{\mathrm{a}}$, SsSw2, SsHn, SsHb \\
2 & $40-60$ & 9 & $\mathrm{SsBa}, \mathrm{SsMk}, \mathrm{SsRj}, \mathrm{SsMt}, \mathrm{SsSt}, \mathrm{SsA1}, \mathrm{SsKr}, \mathrm{SsPr}, \mathrm{SsRt}$ \\
3 & $60-80$ & 20 & $\begin{array}{l}\text { SsLd1, SsLa, SsHs1, SsGj, SsBd, SsSp, SsCk, SsJg, SsBp, SsBm, SsSd, SsBr, SsMd, } \\
\text { SsAd, SsBd1, SsBn, SsLw, SsSb, SsKa, SsAg }\end{array}$ \\
4 & $80-100$ & 14 & $\begin{array}{l}\text { SsFd, SsPn, SsBt2, SsHs2, SsMa, SsSw1, SsDt, SsM1, SsMo, SsLd2, SsMh, SsJa, SsSh, } \\
\text { SsBe2 }\end{array}$ \\
& $>100$ & 11 & SsBh2, SsAm, SsBt1, SsSe, SsBj, SsHr, SsCw, SsMw, SsSi, SsBe3, SsKt \\
\hline
\end{tabular}

AUDPC, area under disease progression curve.

${ }^{a}$ Isolates in red were selected for further biochemical analysis. 


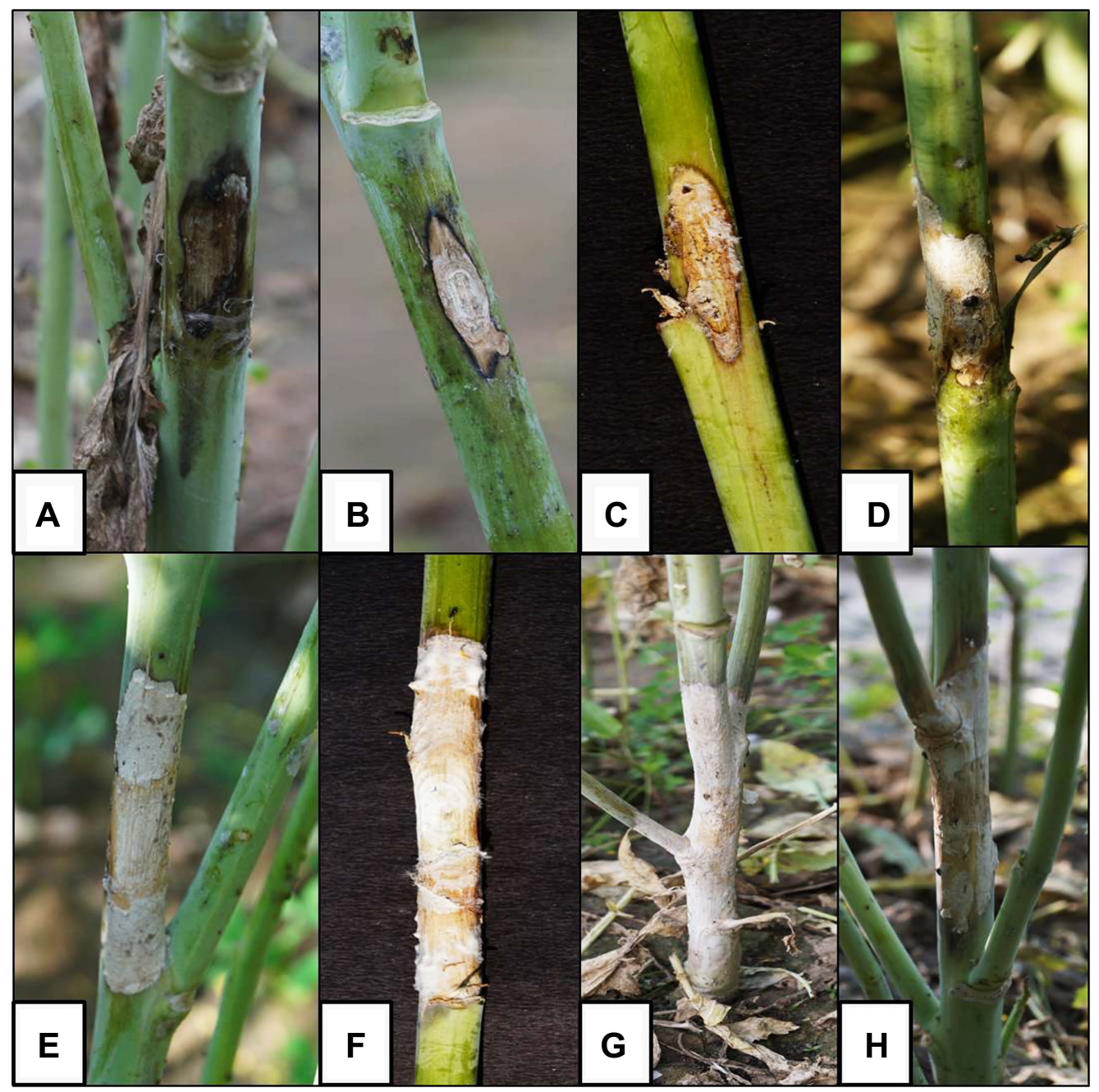

Fig. 1. Initial symptoms (A) and various kinds on lesions (B-H) formed by different isolates on Brassica juncea cv. RL-1359.

tively.

Total acids production. As the fungal mycelium grew, it produced various acids which diffused through the media and changed the colour of BPB from violet to yellow (Fig. 3 ). The $\mathrm{Y} / \mathrm{C}$ ratio served as the measure of total acids production and the isolates exhibited a substantial amount of variability in total acids production with the isolate $\mathrm{SsHr}$ and $\mathrm{SsBe} 2$ having the highest $\mathrm{Y} / \mathrm{C}$ ratio (0.94) and isolate SsBa having the lowest one (0.44).

Oxalic acid analysis. The results revealed that the mean oxalic acid production ranged between $927.9(\mathrm{SsBa})$ and 6,060.5 (SsBe2) $\mu \mathrm{g}$ oxalic acid/g dried mycelium. Thus, a significant variation was observed among the isolates w.r.t. oxalic acid production (Table 4). A high positive correlation was found between oxalic acid and total acids production $\left(r^{2}=0.9\right)$. On comparing the trend of oxalic acid production to that of AUDPC of these isolates (Fig. 4), it was observed that overall trend of oxalic acid coordinated with that of AUDPC. Except for four isolates, SsRt, SsSd, $\mathrm{SsLw}$, and $\mathrm{SsSb}$, all the isolates were having oxalic acid production complimenting their AUDPC value $\left(r^{2}=0.7\right)$.

PG and PME enzyme analysis. All the isolates varied with respect to the enzyme activity (Table 4). The highest PG enzyme activity was observed in culture filtrate of isolate SsSd $(9.44 \mu$ moles of reducing sugar released $/ \mathrm{ml}$ enzyme/min) while the lowest $(0.41 \mu$ moles of reducing sugar released $/ \mathrm{ml}$ enzyme $/ \mathrm{min}$ ) was observed for isolate $\mathrm{SsSw} 2$. In between these, the isolates $\mathrm{SsSw} 2, \mathrm{SsBh} 1$ and $\mathrm{SsMh}$ exhibited lower activity and $\mathrm{SsAm}, \mathrm{SsSd}, \mathrm{SsBr}$, $\mathrm{SsHr}$, SsLw, and SsBe2 exhibited higher enzyme activity. The highest PME activity was observed in the isolate $\mathrm{SsSd}$ (42.56 methoxyl groups liberated in $\mu$ equivalents $/ \mathrm{min} / \mathrm{ml}$ ) and the lowest was observed in isolate SsBd (26.44 me- 


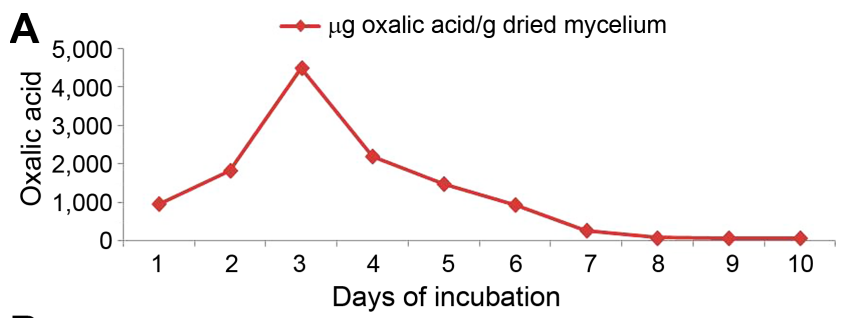

B
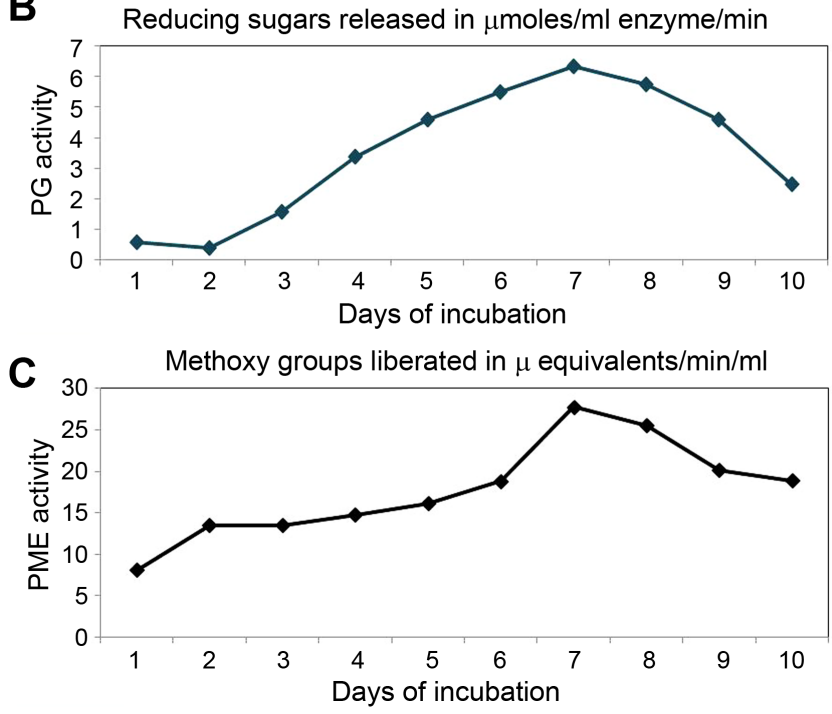

Fig. 2. Oxalic acid production (A), polygalacturonase (PG) (B), and pectin methyl esterase (PME) enzyme activity $(\mathrm{C})$ with respect to growth of Sclerotinia sclerotiorum.

thoxyl groups liberated in $\mu$ equivalents $/ \mathrm{min} / \mathrm{ml}$ ). Activities of all the other isolates ranged in between with $\mathrm{SsBh} 2$ and SsBa exhibiting activity (41.22 methoxyl groups liberated in $\mu$ equivalents $/ \mathrm{min} / \mathrm{ml}$ ) close to highest value and SsMl, SsAl, SsLw, and SsSh exhibiting activity (27.78 methoxyl groups liberated in $\mu$ equivalents $/ \mathrm{min} / \mathrm{ml}$ ) near to the lowest value.

Unlike oxalic acid, overall trend of the activity of both the pectinases did not coordinated well with that of the AUDPC values of the isolates (Fig. 4). Correlation coefficient values of PG and PME with the AUDPC values were 0.4 and zero, respectively. The enzyme activity was found to be indicating no robust correlation with pathogenic aggressiveness. Isolates $\mathrm{SsBh} 1, \mathrm{SsSw} 2, \mathrm{SsBa}$, and $\mathrm{SsRj}$ had lower AUDPC values and their PG activity was also on the lower side, $\mathrm{SsBm}, \mathrm{SsSp}$, and $\mathrm{SsBp}$ are in the mid zone of AUDPC and PG enzyme activity values and $\mathrm{SsBe} 2, \mathrm{SsHr}$, and SsAm had higher AUDPC values and their enzyme activity is also higher. Except for the mentioned isolates, for other isolates, AUDPC values did not correspond to their enzyme activity values. Isolate $\mathrm{SsHr}$ having second highest AUDPC value and isolate SsSw2 having second lowest

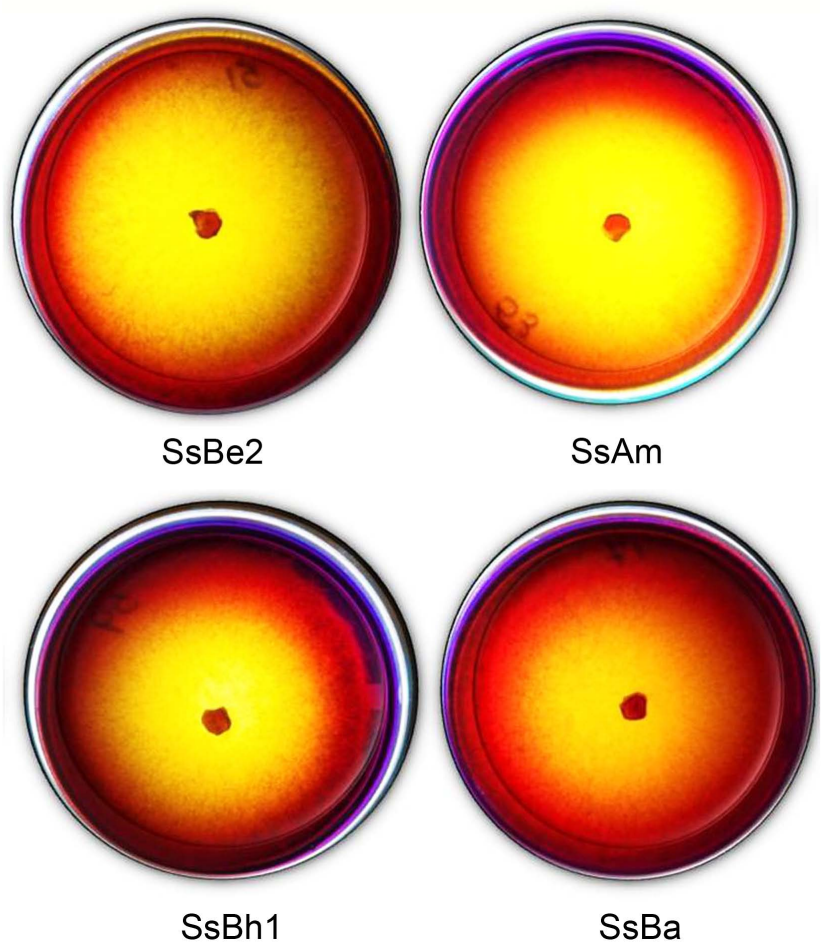

Fig. 3. Yellow colour developed due to acid production by growing mycelium of Sclerotinia sclerotiorum in bromophenol blue amended potato dextrose agar medium.

AUDPC possessed same activity of PME.

\section{Discussion}

The results gave us a deeper and detailed knowledge of pathogenic determinants produced by $S$. sclerotiorum. As 58 isolates were analyzed in this study; the variation present in the lesion lengths and disease progression of different isolates on same cultivar, under same conditions, point towards the underlying variation in the pathogenic aggressiveness of these isolates. For resistance breeding to be a success, these underlying differences within the pathogen population are important to be known so that stable and reliable sources of resistance can be identified and selected to be carried forward in these programs.

During compatible interaction with its host, S. sclerotiorum secretes a full array of CWDEs to facilitate its penetration, carry out tissue maceration and degradation of various cell-wall components (Riou et al., 1991). Pectinases secreted by S. sclerotiorum play major role in lysis and degradation as pectin is the major component of plant cell wall and middle lamella. In addition to these enzymes, the toxin secreted by this fungus: oxalic acid, is known to play a piv- 
Table 4. Ratio of diameter of the yellow colour developed (Y) and diameter of the colony (C) for total acids production

\begin{tabular}{|c|c|c|c|c|c|}
\hline S. no. & Isolate & $\mathrm{Y} / \mathrm{C}$ & $\begin{array}{l}\text { Oxalic acid } \\
(\mu \mathrm{g} / \mathrm{g} \text { dried } \\
\text { mycelium })\end{array}$ & $\begin{array}{c}\text { Polygalacturonase } \\
\text { (reducing sugar released in } \\
\mu \text { moles/ml enzyme/min) }\end{array}$ & $\begin{array}{l}\text { Pectin methyl esterase } \\
\text { ( } \mu \text { equivalents of methoxy } \\
\text { groups liberated } / \mathrm{min} / \mathrm{ml} \text { ) }\end{array}$ \\
\hline 1 & SsLd1 & $0.69 \mathrm{~g}^{\mathrm{a}}$ & $1,949.2 \mathrm{ij}$ & $6.19 \mathrm{de}$ & 31.36 ghi \\
\hline 2 & SsBh1 & $0.56 \mathrm{i}$ & 1,243.9 lm & $0.89 \mathrm{~m}$ & 30.47 hi \\
\hline 3 & $\mathrm{SsBh} 2$ & $0.88 \mathrm{~b}$ & $5,017.2 \mathrm{bc}$ & $2.88 \mathrm{jk}$ & $41.22 \mathrm{ab}$ \\
\hline 4 & $\mathrm{SsBa}$ & $0.44 \mathrm{k}$ & $927.9 \mathrm{~m}$ & $2.50 \mathrm{kl}$ & $41.22 \mathrm{ab}$ \\
\hline 5 & SsAm & $0.82 \mathrm{bc}$ & $4,478.6 \mathrm{de}$ & $8.50 \mathrm{ab}$ & $38.98 \mathrm{abcd}$ \\
\hline 6 & SsLa & $0.50 \mathrm{j}$ & $1,131.9 \mathrm{~lm}$ & $3.67 \mathrm{hij}$ & $39.88 \mathrm{abc}$ \\
\hline 7 & $\mathrm{SsBd}$ & $0.76 \mathrm{def}$ & $2,679.6 \mathrm{~lm}$ & $4.87 \mathrm{fg}$ & $26.44 \mathrm{j}$ \\
\hline 8 & $\mathrm{SsSp}$ & 0.77 cde & $2,875.6 \mathrm{~lm}$ & $4.95 \mathrm{fg}$ & 34.50 efg \\
\hline 9 & SsMk & $0.59 \mathrm{hi}$ & $1,261.6 \mathrm{~g}$ & $6.96 \mathrm{~cd}$ & $34.50 \mathrm{efg}$ \\
\hline 10 & SsSw2 & $0.61 \mathrm{hi}$ & $1,310.4 \mathrm{ef}$ & $0.41 \mathrm{~m}$ & $31.81 \mathrm{gh}$ \\
\hline 11 & SsRj & $0.47 \mathrm{jk}$ & 1,109.1 def & $3.62 \mathrm{ijk}$ & 37.19 cde \\
\hline 12 & $\mathrm{SsDt}$ & $0.63 \mathrm{~h}$ & $1,671.2 \mathrm{a}$ & $3.03 \mathrm{jk}$ & $33.16 \mathrm{fgh}$ \\
\hline 13 & SsMl & $0.88 \mathrm{~b}$ & $5,034.1 \mathrm{~h}$ & $4.77 \mathrm{gh}$ & $27.78 \mathrm{ij}$ \\
\hline 14 & $\mathrm{SsBm}$ & $0.63 \mathrm{~h}$ & $1,940.2 \mathrm{~h}$ & 4.70 ghi & $35.84 \mathrm{def}$ \\
\hline 15 & SsMh & $0.72 \mathrm{efg}$ & $2,577.5 \mathrm{kl}$ & $1.42 \mathrm{~lm}$ & $38.53 \mathrm{bcd}$ \\
\hline 16 & $\mathrm{SsSd}$ & $0.78 \mathrm{cde}$ & $3,432.7 \mathrm{jk}$ & $9.44 \mathrm{a}$ & $42.56 \mathrm{a}$ \\
\hline 17 & SsAl & $0.71 \mathrm{fg}$ & $2,058.1 \mathrm{bc}$ & $5.32 \mathrm{efg}$ & $27.78 \mathrm{ij}$ \\
\hline 18 & $\mathrm{SsBr}$ & $0.63 \mathrm{~h}$ & $1,916.4 \mathrm{ij}$ & $8.03 \mathrm{bc}$ & $35.84 \mathrm{def}$ \\
\hline 19 & $\mathrm{SsHr}$ & $0.94 \mathrm{a}$ & $5,070.3 \mathrm{~h}$ & $8.03 \mathrm{bc}$ & 31.36 ghi \\
\hline 20 & SsRt & $0.81 \mathrm{~cd}$ & $4,189.1 \mathrm{i}$ & $5.63 \mathrm{efg}$ & $31.81 \mathrm{gh}$ \\
\hline 21 & SsLw & $0.81 \mathrm{~cd}$ & $4,296.2 \mathrm{ij}$ & $8.75 a b$ & $27.78 \mathrm{ij}$ \\
\hline 22 & $\mathrm{SsSh}$ & $0.88 \mathrm{~b}$ & $4,655.8 \mathrm{~b}$ & $6.34 \mathrm{de}$ & $27.78 \mathrm{ij}$ \\
\hline 23 & $\mathrm{SsSb}$ & $0.81 \mathrm{~cd}$ & $4,082.0 \mathrm{~cd}$ & $5.95 \mathrm{def}$ & $35.84 \mathrm{def}$ \\
\hline 24 & $\mathrm{SsBe} 2$ & $0.94 \mathrm{a}$ & $6,060.5 \mathrm{f}$ & $8.20 \mathrm{~b}$ & $31.81 \mathrm{gh}$ \\
\hline
\end{tabular}

${ }^{a}$ Different small letters indicate significant difference based on least significant at $P<0.05$.

otal role in disease development and thus is a key pathogenicity determinant (Lumsden, 1979). Besides oxalic acid, is also known to release other dicarboxylic organic acids such as succinic, malic, fumaric, and glycolic acids (Vega et al., 1970). In this study, oxalic acid production and disease progression (as AUDPC) were highly positively correlated. The isolates on higher side of the AUDPC values were also on the higher side of oxalic acid production and vice-versa for lower side. This suggests that pathogenic aggressiveness of $S$. sclerotiorum has a high dependency on oxalic acid production. To our knowledge, this is the first study to have correlated oxalic acid production in S. sclerotiorum isolates to its pathogenic aggressiveness on Brassica juncea. The evidence for the involvement and such dependence of pathogenicity on oxalic acid is based on its recovery from infected tissues (De Bary, 1866; Marciano et al., 1983) and the correlation between disease score/severity and oxalic acid production in some previous studies. Durman et al. (2005) reported significant differences amongst different mycelial compatibility groups' w.r.t. their oxalic acid and other organic acids production. S. sclerotiorum oxalic acid deficient mutants were non-pathogenic even when they were having their full battery of CWDEs on dry beans whereas their revertant strains, that regained their ability to produce oxalic acid displayed normal virulence patterns (Godoy et al., 1990). The mechanism(s) by which oxalic acid aids in pathogenicity are; it provides optimum conditions for CWDEs to work by lowing $\mathrm{pH}$ to 4-5, helps in escaping the attack of polygalaturonase inhibiting proteins (Favaron et al., 2004), chelates $\mathrm{Ca}^{2+}$ and makes way for PG to hydrolyse the pectates and suppresses the oxidative burst in host plants (Guimaraes and Stotz, 2004). This explains the correlation and the similar trend obtained between the aggressiveness and oxalic acid secreted by the isolates in this study.

De Bary (1866) was the first to suggest that extracellular enzymes may be involved in the infection process of plant pathogenic fungi. Of the numerous CWDEs produced by 


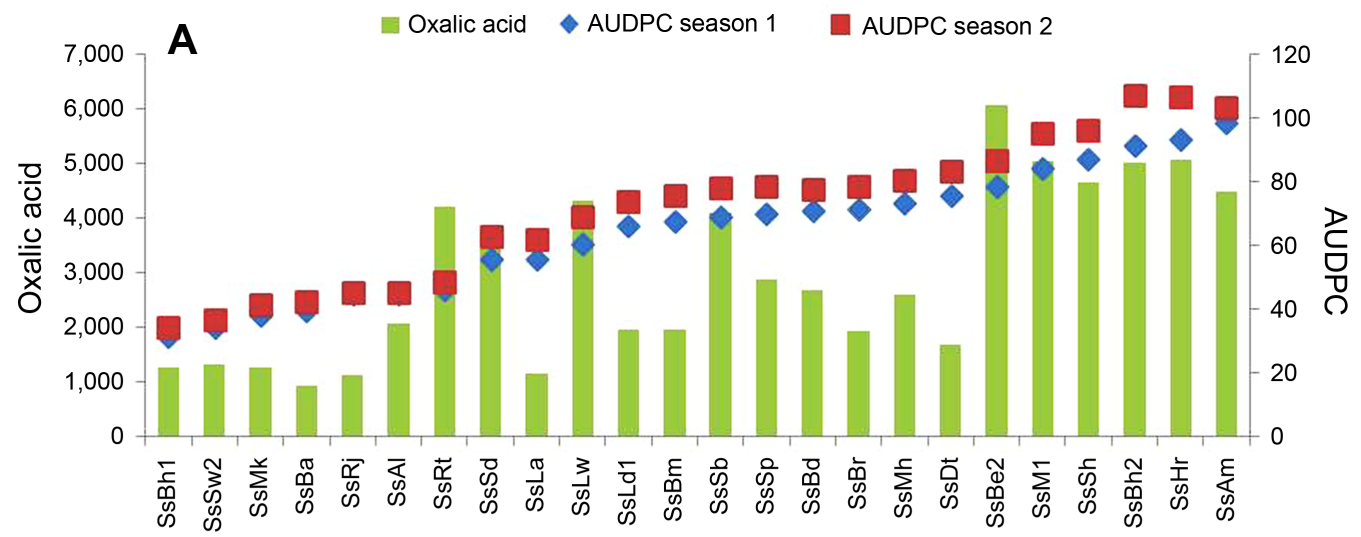

S. sclerotiorum isolates

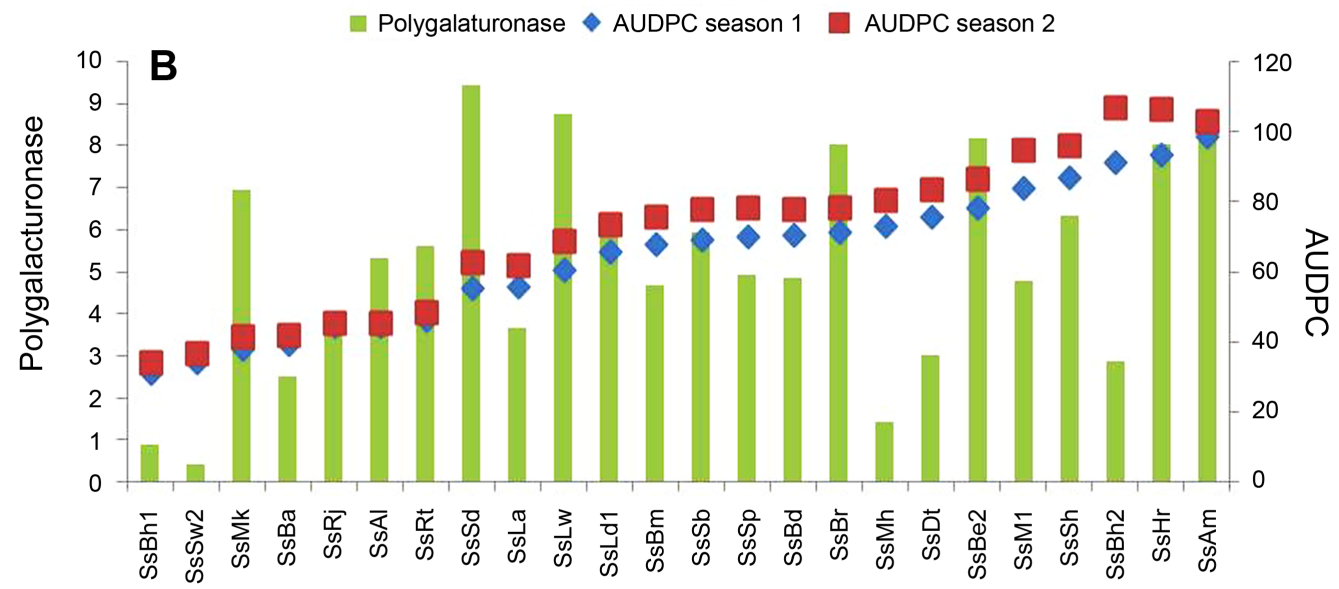

S. sclerotiorum isolates

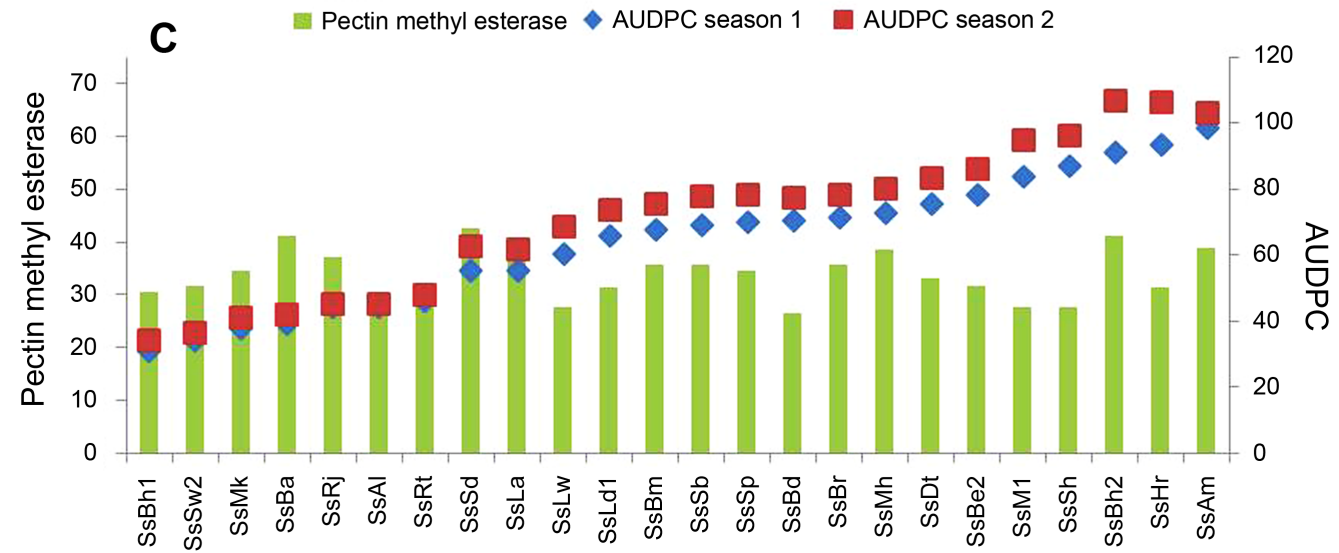

S. sclerotiorum isolates

Fig. 4. Relation of oxalic acid production (A), polygalaturonase (B) and pectin methyl esterase activity (C) and area under disease progression curve (AUDPC) of Sclerotinia sclerotiorum isolates.

plant pathogenic fungi, most research has focused on the pectin degrading enzymes. This is because the pectinases are typically produced first, in the largest amounts and are the only CWDEs capable of macerating plant tissue and killing plant cells on their own. PME carries out the demethylation of esterified pectin and thus makes it available for other enzymes, like polygalaturonase, for further break down to galacturonic acid monomers. The isolates used in 
this study varied considerably in pectinase enzyme activity but a correlation could not be worked out with AUDPC of the isolates. In addition to these, many other CWDEs are produced by this fungus. This may be attributed to the fact that pathogenic aggressiveness is not governed by these enzymes only but is determined by various other factors involved along with these pectinases. Many other CWDEs (cellulases, hemicellulases, xylanases, glucanases, proteases, etc.) are produced by this fungus; thus, these particularly studied enzymes won't be acting and governing the pathogenicity just on their own. The expression of most CWDEs is tightly regulated at the transcription level by the availability of carbon and/or nitrogen sources and also the pH levels (Rollins and Dickman, 2001). A study in Saskatchewan was conducted using 114 isolates of $S$. sclerotiorum for their disease causing capacity and pectinase enzyme production (Morrall et al., 1972, 1976) and concluded that an endo-PG was the most prevalent of the entire pectic enzymes but there was no significant positive correlation between isolate pathogenicity and its pectinolytic enzyme activities. This also suggests that any one pectolytic enzyme might not be rendered soleley responsible for the pathogenicity and a programmed play of lytic enzymes is there which is governing the pathogenicity. During interaction with the host, the monomers released from host tissues degradation brought about by pathogenic origin lytic enzyme action and the presence of other pathogenicity determinants might be acting as inducers for stimulating more production of pectinases and thus we were not able to get that in-vivo.

This study gave us a clear insight of difference existing within the isolates of $S$. sclerotiorum with respect to their pathogenic aggressiveness, which could be very well correlated to their oxalic acid production but not so to the pectinase enzyme activity. Thus, the oxalic acid production can be used as a biochemical marker to study different isolates and their pathogenic aggressiveness may be anticipated. This will ensure involvement of aggressive isolates of $S$. sclerotiorum in the screening programs and thus can be of real help to identify robust resistance sources. The assay being simple and easy to carry out will surely help breeders and pathologists to identify aggressive isolates before taking the things to field testing, which will save time and other resources. As far as pectinases' activity is concerned, further studies may be required to carry out for analyzing the whole enzymatic profile during the host-pathogen interaction so that it come out more clearly which enzymes or enzyme combinations have more effect on governing the pathogenicity.

\section{Conflicts of Interest}

No potential conflict of interest relevant to this article was reported.

\section{References}

Ando, K., Grumet, R., Terpstra, K. and Kelly, J. D. 2007. Manipulation of plant architecture to enhance crop disease control. CAB Rev. 2:1-8.

Annis, S. L. and Goodwin, P. H. 1997. Recent advances in the molecular genetics of plant cell wall-degrading enzymes produced by plant pathogenic fungi. Eur. J. Plant Pathol. 103:114.

Boland, G. J. and Hall, R. 1994. Index of plant hosts of Sclerotinia sclerotiorum. Can. J. Plant Pathol. 16:93-100.

Bolton, M. D., Thomma, B. P. H. J. and Nelson, B. D. 2006. Sclerotinia sclerotiorum (Lib.) de Bary: biology and molecular traits of a cosmopolitan pathogen. Mol. Plant Pathol. 7:116.

Buchwaldt, L., Li, R., Hegedus, D. D. and Rimmer, S. R. 2005. Pathogenesis of Sclerotinia sclerotiorum in relation to screening for resistance. In: Proceedings of the 13th International Sclerotinia Workshop, p. 22. University of California Cooperative Extension, Salinas, CA, USA.

Cessna, S. G., Sears, V. E., Dickman, M. B. and Low, P. S. 2000. Oxalic acid, a pathogenicity factor for Sclerotinia sclerotiorum, suppresses the oxidative burst of the host plant. Plant Cell 12:2191-2199.

De Bary, A. 1866. Morphologie und physiologie der pilze, flechten, und myxomyceten. Hofmeister's handbook of physiological botany. Vol. 2. Engelmann, Leipzig, Germany. 316 pp. (in German).

Deese, C. D. and Stahmann, M. A. 1962. Pectic enzymes in Fusarium-infected susceptible and resistant tomato plants. Phytopathology 52:255-260.

Durman, S. B., Menendez, A. B. and Godeas, A. M. 2005. Variation in oxalic acid production and mycelial compatibility within field populations of Sclerotinia sclerotiorum. Soil Biol. Biochem. 37:2180-2184.

Favaron, F., Sella, L. and D'Ovidio, R. 2004. Relationships among endo-polygalacturonase, oxalate, $\mathrm{pH}$, and plant polygalacturonase-inhibiting protein (PGIP) in the interaction between Sclerotinia sclerotiorum and soybean. Mol. PlantMicrobe Interact. 17:1402-1409.

Godoy, G., Steadman, J. R., Dickman, M. B. and Dam, R. 1990. Use of mutants to demonstrate the role of oxalic acid in pathogenicity of Sclerotinia sclerotiorum on Phaseolus vulgaris. Physiol. Mol. Plant Pathol. 37:179-191.

Guimarães, R. L. and Stotz, H. U. 2004. Oxalate production by Sclerotinia sclerotiorum deregulates guard cells during infection. Plant Physiol. 136:3703-3711.

Li, C. X., Li, H., Sivasithamparam, K., Fu, T. D., Li, Y. C., Liu, 
S. Y. and Barbetti, M. J. 2006. Expression of field resistance under Western Australian conditions to Sclerotinia sclerotiorum in Chinese and Australian Brassica napus and Brassica juncea germplasm and its relation with stem diameter. Aust. J. Agric. Res. 57:1131-1135.

Li, C. X., Liu, S. Y., Sivasithamparam, K. and Barbetti, M. J. 2008. New sources of resistance to Sclerotinia stem rot caused by Sclerotinia sclerotiorum in Chinese and Australian Brassica napus and B. juncea germplasm screened under Western Australian conditions. Australas. Plant Pathol. 38:149-152.

Lumsden, R. D. 1979. Histology and physiology of pathogenesis in plant diseases caused by Sclerotinia species. Phytopathology 69:890-896.

Marciano, P., Di Lenna, P. and Magro, P. 1983. Oxalic acid, cell wall-degrading enzymes and $\mathrm{pH}$ in pathogenesis and their significance in the virulence of two Sclerotinia sclerotiorum isolates on sunflower. Physiol. Plant Pathol. 22:339-345.

Miller, G. L. 1959. Use of dinitrosalicylic acid reagent for determination of reducing sugar. Anal. Chem. 31:426-428.

Morrall, R. A. A., Duczek, J. and Sheard, J. W. 1972. Variations and correlations within and between morphology, pathogenicity, and pectolytic enzyme activity in Sclerotinia from Saskatchewan. Can. J. Bot. 50:767-786.

Morrall, R. A. A., Dueck, J., McKenzie, D. L. and McGee, D. C. 1976. Some aspects of Sclerotinia sclerotiorum in Saskatchewan, 1970-75. Can. Plant Dis. Surv. 56:56-62.

Riou, C., Freyssinet, G. and Fevre, M. 1991. Production of cell wall-degrading enzymes by the phytopathogenic fungus Sclerotinia sclerotiorum. Appl. Environ. Microbiol. 57:14781484.

Rollins, J. A. and Dickman, M. B. 2001. pH signaling in Sclerotinia sclerotiorum: identification of a pacC/RIM1 homolog. Appl. Environ. Microbiol. 67:75-81.
Saharan, G. S. and Mehta, N. 2008. Sclerotinia diseases of crop plants: biology, ecology and disease management. Springer, Dordrecht, The Netherlands. 486 pp.

Sharma, S., Harmandeep and Soni, G. 2001a. Interaction of phenolic compounds with pectinases from Sclerotinia sclerotiorum. Indian Phytopathol. 54:167-170.

Sharma, S., Yadav, J. L. and Sharma, G. R. 2001b. Effect of various agronomic practices on the incidence of white rot of Indian mustard caused by Sclerotinia sclerotiorum. J. Mycol. Plant Pathol. 31:83-84.

Steadman, J. R. 1983. White mold: a serious yield-limiting disease of bean. Plant Dis. 67:346-350.

Vega, R. R., Corsini, D. and Le Tourneau, D. 1970. Nonvolatile organic acids produced by Sclerotinia sclerotiorum in synthetic liquid media. Mycologia 62:332-338.

Waksman, G., Keon, J. P. and Turner, G. 1991. Purification and characterization of two endopolygalacturonases from Sclerotinia sclerotiorum. Biochem. Biophys. Acta. 1073:43-48.

Xu, X.-Q. and Zhang, Z.-Q. 2000. Kinetic spectrophotometric determination of oxalic acid based on the catalytic oxidation of bromophenol blue by dichromate. Microchim. Acta 135:169172.

Yadav M. S., Yadava, D. K., Nasim, A., Saroj, S. and Bambawale, O. M. 2011. Sclerotinia rot: a threat to rapeseed-mustard and virulence assessment of released varieties against Sclerotinia sclerotiorum. Plant Dis. Res. 26:202.

Zhao, J., Peltier, A. J., Meng, J., Osborn, T. C. and Grau, C. R. 2004. Evaluation of sclerotinia stem rot resistance in oilseed Brassica napus using a petiole inoculation technique under greenhouse conditions. Plant Dis. 88:1033-1039.

Zhou, T. and Boland, G. J. 1999. Mycelial growth and production of oxalic acid by virulent and hypovirulent isolates of Sclerotinia sclerotiorum. Can. J. Plant Pathol. 21:93-99. 